ture, as to render the task of deciphering their mutual relationships and determining their exact systematic positions an exceedingly difficult, if not an impossible one. At the same time, however, it does not appear to us that the existence of these puzzling and aberrant types need interfere in the least degree with the commonly-accepted classification of the Ungulates, although there may be legitimate doubt as to the propriety of including the Macrauchenias among the Perissodactyles, instead of retaining them with the Toxodonts as a special group, exhibiting on the one hand many generalized features, coupled with extreme specialization in other respects.

R. L.

\section{THE CHANGEFULNESS OF TEMPERATURE AS AN ELEMENT OF CLIMATE.}

$\mathrm{NE}$ of the features in which the climates of great continents most contrast with those of oceanic islands, and those of higher latitudes with the climates of the tropics, is the greater range through which the temperature varies between night and day, and between winter and summer. Another, perhaps not less important, is the greater changefulness of the temperature from day to day. Both of these are comprised under the general expression variabiiity of temperature, ${ }^{1}$ and they are similar in their effects on living organisms, but they depend on very different causes, and in their local association are often manifested in very different degrees; places with a great annual and diurnal range of temperature, displaying great constancy of climate at any given season of the year, while others, at which the former variations are moderate in amount, are, nevertheless, subject to irregular vicissitudes of considerable magnitnde. The Punjab and Sind may be cited as examples of the former class, Western and Central Europe of the latter.

Now, although from a sanitary point of view these two kinds of variation are of equal importance, the degrees in which they have respectively engaged the attention of climatologists and others are strikingly different. While the daily and annual range of temperature of all the more important and many minor places that have furnished meteorological registers are now well known, or are easily ascertainable from published records, the first systematic inquiry into the changefulness of temperature as an element of climate was that made by Prof. Hann in a memoir published in the Sitzungsberichte of the Vienna Academy of Sciences in I 875. In this paper, Dr. Hann tabulated the results of ninety stations, seven of which are situated in the southern hemisphere, and the remainder chiefly in Europe, Siberia, Canada, and the United States. The extraction of the data was not a little laborious, since it consisted in taking out from the daily registers, of generally from five to ten years, the differences of the mean temperatures of every pair of successive days throughout the whole period; then classifying them according to algebraic sign, as rises or falls of temperature, and also, in certain cases, according to their incremental values. The means of these different categories were then taken month by month, and the results are given in numerous tables in the memoir. The changefulness of temperature at any given place is the general mean of all changes during the period considered, irrespective of their being rise or fall. As instances of these, I take the following three stations, representing respectively the climates of Siberia, England, and Canada. They show

I The term "variability" of temperature, adopted by Mr. Scott for the element now in question, has been already used in so many different senses, that in this paper 1 have adopted in preference the term "changefulness," which is not open to the same objection. the average change of any two consecutive days on the Fahrenheit scale.

\begin{tabular}{|c|c|c|c|c|}
\hline & & Barnaul. & Oxford. & Toronto. \\
\hline $\begin{array}{ll}\text { January } & \ldots \\
\text { February } & \ldots \\
\text { March } & \ldots \\
\text { April } & \ldots \\
\text { May } & \ldots \\
\text { June } & \ldots \\
\text { July } & \ldots \\
\text { August } & \ldots \\
\text { September... } \\
\text { October } & \ldots \\
\text { November } & \ldots \\
\text { Necember } & \ldots\end{array}$ & \begin{tabular}{l|}
$\ldots$ \\
$\ldots$ \\
$\ldots$ \\
$\ldots$ \\
$\ldots$ \\
$\ldots$ \\
$\cdots$ \\
$\ldots$ \\
$\ldots$ \\
$\ldots$ \\
$\ldots$ \\
$\ldots$
\end{tabular} & $\begin{array}{r}8 \cdot 8 \\
8 \cdot 5 \\
7 \cdot 2 \\
4 \cdot 7 \\
5 \cdot 6 \\
4 \cdot 3 \\
3 \cdot 4 \\
3 \cdot 2 \\
4 \cdot 5 \\
5 \cdot 6 \\
9 \cdot 0 \\
10 \cdot 1\end{array}$ & $\begin{array}{l}3 \cdot 4 \\
3 \cdot I \\
2 \cdot 9 \\
2 \cdot 9 \\
3 \cdot 1 \\
2 \cdot 7 \\
2 \cdot 3 \\
2 \cdot 5 \\
2 \cdot 5 \\
3 \cdot 4 \\
3 \cdot 6 \\
3 \cdot 8\end{array}$ & $\begin{array}{l}6 \cdot 8 \\
6 \cdot 8 \\
4 \cdot 9 \\
4 \cdot 0 \\
3 \cdot 8 \\
3 \cdot 8 \\
3 \cdot 6 \\
3 \cdot 2 \\
4 \cdot 5 \\
4 \cdot 1 \\
4 \cdot 5 \\
6 \cdot 7\end{array}$ \\
\hline Year & $\ldots$ & $6 \cdot 3$ & $3^{\cdot I}$ & 47 \\
\hline
\end{tabular}

These three stations serve to illustrate the fact, amply confirmed by the general tables, that temperature is subject to greater and more rapid changes in the winter than in the summer; either December or January being, as a rule, the month of greatest variability.

Since the publication of this memoir, the inquiry thus started by Dr. Hann has been followed up by several writers with especial reference to particular countries. Prof. O. Döring, for instance, has thus discussed the statistics of the Argentine Republic; Herr E. Wahlén, those of 18 stations in Russia; Dr. V. Kremer, those of 57 stations in Northern Germany; and Mr. Robert Scott, those of 7 observatories in the British Isles, at which the temperature has been recorded by thermographs since I 869. These are Valentia, Armagh, Glasgow, Aberdeen, Falmouth, Stonyhurst, and Kew. At all these stations the variation was found to be less than at Oxford; but this may be partly due to the longer period ( 5 years) over which the records extend, and partly also to the fact that the daily means compared are those of the twentyfour hourly measurements of the thermograph curve, whereas the Oxford register was for Io years only, and the observations less numerous. On the general average of the year, it was greatest at $\operatorname{Kew}\left(2^{\circ} \cdot 7\right)$, and least at Falmouth and Valencia $\left(1^{\circ} .9\right)$.

Finally, Dr. Hann has resumed the subject in a memoir published in the Transactions of the Vienna Academy, ${ }^{1}$ in which he discusses the temperature records of 66 stations in the Austrian Empire and the adjacent territories, of which one-half extend over from 10 to 20 years, and the majority of the remainder over at least five years; all, however, are corrected to the period I $871-80$. In the case of Vienna, not less than 9i years have been included in the reckoning, and this register affords the means of comparing the results of any decade with those of a long period.

The first point that stands out in the results of this discussion is that even a period of ten years is insufficient to give more than an approximate value. The general mean change at Vienna, between any two consecutive days, is $3^{\circ} 4 \mathrm{~F}$, but in the decade $186 \mathrm{I}-70$ it was only $3^{\circ} 26$, whereas in the decades $180 \mathrm{I}-10$ and I $871-80$ it averaged $3^{\circ} .53$. The means of the individual months show much greater variation; that of December especially, ranging between $3^{\circ} \cdot 2$ and $4^{\circ} \cdot 3$ in different decennia, or through 30 per cent. of the general mean for the month. It is evident that when computed from shorter periods than ten years the discrepancies will

I "Die Veränderlichkeit der Temperatur in Oesterreich," von J. Hann, W.M.K. Akad., aus dem lviii.Bande der Mat. Naturwiss. Classe der $h$. Akad. d. Wissenschaften. 
be still greater. In order, therefore, to obtain comparable values, even for neighbouring stations, it is essential that the data compared should be those of the same interval.

Both as regards season and amount, the changefulness of temperature depends very greatly on local geographical circumstances, so that neighbouring places very often differ greatly from each other. In Europe it increases from west to east and from south to north, in both cases towards the interior of the continent. It increases also on the whole with altitude, but very irregularly, being great on exposed plateaux, and comparatively small on mountain peaks. Places situated in valleys show very great differences, according to their exposure. Among the Austrian stations, those on the southern slopes of the Alps have the greatest vicissitudes, owing to the warmth they acquire in sunny weather and the consequent greater fall of temperature when a change of weather sets in. In general the changes of temperature at high elevations are greater than at low altitudes in summer, but less in the winter season. In the high mountain valleys in spring the changes are much smaller than on the neighbouring plains.

In the British Isles, Mr. Scott found that the number of rises exceeding $5^{\circ}$ between any two consecutive days was greater than the number of falls of the same amount, and also that the mean value.of the rises exceeds that of the falls. In Austria, also, except in the Southern Tyrol and on the coasts of the Adriatic, rapid rises are greater than rapid falls in the winter, and less in the summer; but on the whole the former preponderate. In the south, however, rapid falls are greater than rapid rises at all times of year, and therefore also on the mean of the year. This peculiarity is a still more marked characteristic of lower latitudes, since in Northern India it was found that rapid falls are about three times as numerous as rapid rises, and on the whole greater in amount.

The duration of rises of temperature is somewhat greater than that of falls, and both are rather greater at mountain stations than at low levels. Thus the passage of a wave of temperature, on the mean of the two stations Klagenfurt and Salzburg, occupies, on an average, 4.56 days, on the Sonnblick 4.93 days ; or, in other words, $6 \frac{1}{2}$ waves pass within the month at the higher and 7 at the lower stations. The longest period of continuous cooling that occurred at any station was ten days at the mountain observatory of Hoch Obir, and the longest continuous rise of temperature ten days at Klagenfurt. There is a marked annual periodicity in the length of the temperature waves, with two epochs of maximum, viz. in March and September, and two of minimum, in July and December. From the data afforded by certain stations in Austria and Saxony, Dr. Hann computes the following formula for their annual variation in Central Europe-

$$
4.813+0^{\prime} 138 \sin \left(26^{\circ} 45^{\prime}+x\right)+0.164 \sin \left(318^{\circ} 27^{\prime}+2 x\right) .
$$

The last subject investigated in Dr. Hann's memoir is the question whether the inter-diurnal changefulness of temperature shows any periodical variation during the sun-spot period; for which purpose he takes the 90 years' registers of Vienna, Wilna, and Warsaw. He finds that on the mean of these stations a certain minute variation is indeed apparent, but it is one of two maxima and two minima, and the whole range is so small that it is doubtful whether it is other than fortuitous.

In the foregoing paragraphs only a few of the more important results of Prof. Hann's investigation have been noticed. His memoir contains many others of interest, well worthy of study, and forming important contributions to general climatology; and like the original memoir, published seventeen years ago, it will doubtless stimulate others to prosecute the subject. It is especially import- ant from a medical point of view that the statistics of all health resorts should be analyzed in the manner of which Prof. Hann has here given so admirable an example.

H. F. B.

\section{FORESTRY IN AMERICA.'}

$\mathrm{T}$ cannot be said that, as far as the issue of reports and pamphlets on forestry is concerned the Agricultural Department at Washington has been idle; if only this activity would resolve itself into the establishment of a State Forest Service, and the formation of State forests out of the wreck of the former forest wealth of North America!

An important series of papers on forest matters has come to hand, and though they date as far back as I 889 , they are probably new to many of the readers of NATURE.

The first paper is by Dr. James, Professor of Public Finance and Administration in the University of Pennsylvania, and is entitled "The Government in its Relation to Forests." The Professor has evidently studied his subject thoroughly, and the remedy he proposes is the exact counterpart of that which has been so successfully applied to the forests of India. He commences by stating that the forests of any large country not only constitute a large portion of its wealth, but form the indispensable basis of a flourishing manufacturing and commercial industry. They are also one of the most important elements in determining the climatic conditions of a region, and, through these, the distribution of the population, of industrial pursuits, and of disease and health. He states that the value of the forest crop in the United States in 1880 , the census year, was $700,000,000$ dollars $(=£ 140,000,000)$, and that if the value of the total annual output of the mines, quarries, and petroleum wells were added to the estimated value of all steamboats and other craft on American waters, it would still be less than the value of the forest crop, by a sum sufficient to purchase all the canals, telegraph companies, and construct and equip all the telephone lines in the States.

He then shows how Government has fostered agriculture by offering land on easy terms, by establishing model farms and agricultural schools, by improving the breed of stock, by free distribution of seed, and in many other ways; it has also assisted manufactures by the protective tariff, bounties, and exhibitions, \&c.; and that vast sums have been spent by the State on improving rivers and harbours, and on the general means of communication-railroads and roads. Game and fish are also protected by the State, but although from their forests the Americans have been drawing more natural wealth than from all other sources together, yet practically nothing has been done to preserve them from the devastations of selfish people. Besides the great demands on the forests for timber, three-fifths of the people in the States use wood for ordinary domestic fuel, and the value of the wood fuel annually consumed is placed at $325,000,000$ dollars.

Prof. James then treats at length of the vast indirect value of forests in maintaining a steady supply of water in rivers, and preventing floods. He shows that the maintenance of a system of factories and mills dependent on a watercourse becomes impossible when the stream is converted into a mountain torrent for one quarter of the year and is all but dry during another quarter; and instances the River Schuylkill, from which Philadelphia draws its water-supply, where the current has become too shallow and sluggish to carry off the ever-increasing

$x$ " Department of Agriculture, Forestry Division. Bulletin No. 2.-Re-, port on the Forest Condition of the Rocky Mountains, and uther Papers." With a Map showing location of Forest Areas. Second Edition. (Washington: Government Press, 1889.) 